\title{
Hemşirelik Öğrencilerinin Ahlaki Duyarlılıklarının İncelenmesi
}

\author{
The Moral Sensibility of Nursing Students
}

\author{
Türkan KARACA ${ }^{\mathbf{a}}$
}

\begin{abstract}
ÖZET Amaç: Araştırma, hemşirelik öğrencilerinin ahlaki duyarlılıklarının incelenmesi amacıyla tanımlayıcı desende yapıldı. Yöntem: Araştırmanın evreninde 2015-2016 eğitim ve öğretim yllında ve bahar dönemi'nde sağlık yüksekokulu hemşirelik bölümünde kayıtlı 322 öğrenci yer aldı. Çalışmanın örneklemini araştırmaya ilişkin bilgi aldıktan sonra kendi rızasıyla araştırmaya katılan ve veri toplama araçlarını tam olarak dolduran 281 öğrenci oluşturdu. Araştırmada veriler Kişisel Bilgi Formu ve Ahlaki Duyarlılık Anketi kullanılarak toplandı. Verilerin istatistiksel analizinde Mann-Whitney U testi, Kruskal-Wallis testi, ortalama, minumum, maksimum ve yüzdelik hesaplarından yararlanıldı. Bulgular: Araştırmadan elde edilen bulgulara göre hemşirelik öğrencilerin anket puan ortalamalarının $124.20 \pm 31.40$ olduğu saptandı. Ayrıca araştırmada elde edilen sonuçlara göre, ahlaki duyarlılık anketi ile öğrencilerin sınıfları, sosyo-ekonomik düzeyleri, hemşirelik bölümünden memnuniyetleri, etik dersi alma ve etikle ilgili yayın takip etme durumları, etik ikilem yaşama durumları arasında istatistiksel olarak anlamlı bir fark bulundu. Sonuç: Hemşirelik öğrencilerinin ahlaki duyarlılığının artırılması ve buna bağlı olarak etik sorunların farkına varma ve çözümünün bulunulabilmesi için, mezun olmadan önce ve sonra etiğe ilișkin eğitim programlarının geliştirilmesi ve bu konuda daha fazla araştırma yapılması öneriler arasındadır.
\end{abstract}

Anahtar Kelimeler: Ahlaki duyarlılık, Hemşirelik eğitimi, Öğrenci hemşire

\begin{abstract}
Purpose: This study was carried out as a descriptive study to determine the moral sensibility of nursing students. Method: The population of study consisted 264 nursing students who enrolled in vocational courses during the spring semester at School of Health Sciences Nursing Department. The study was carried out with 281 nursing students who were informed by researcher voluntarily participated and completely filled the Moral Sensibility Scale. Data was collected by Demographical Characterics Form and Moral Sensibility Scale. Mann-Whitney U, Kruskal-Wallis, Median and Percentages were used for analysis. Results: According to findings from study, the average scores of the students were obtained $124.20 \pm 31.40$. Students' class, socio-,economic status, satisfaction from nursing department, taking of etic lesson and following of publications related etics had statistical significance between Moral Sensibility Scale. Conclusion: In order to increase the level of moral sensibility of nurses and thus to recognize and solve ethical problems, it is suggested to plan undergraduate and postgraduate education programs.
\end{abstract}

Key words: Moral sensibility, Nurse education, Nurse students

\section{Giris}

Hasta bakımındaki ilerlemeler, dünyadaki global değişimler sağlik uygulamalarına yansımakta ve duruma bağlı olarak her geçen gün etiğe duyulan gereksinim artmaktadır. ${ }^{1}$ Etik, hangi davranışın iyi ve kötü olduğunu, doğru ve yanlış davranışları inceler. ${ }^{2}$ Diğer bir deyişle etik, bireyin davranışlarına esasını oluşturan ahlak ilkelerin bütünüdür. ${ }^{2,3}$ Etik ikilemde kalmak ise bir eylem esnasinda yargida bulunulması gereken durumlarda iki değer arasında karmaşa olmasıdır. ${ }^{4}$ Günlük hayatta birçok etik ikilem ile karşılaşılmakta ve ikilemler karşısında verilen kararlar da toplum üzerinde önemli etkiler yaratmaktadır. Bu durum etik duyarlılığın ve ahlaki değerlerin gelişmiş olduğu bir sağl1k hizmeti sunumuna gereksinim olduğunu ortaya koymaktadır. "Ahlaki değerler, nesneleri, insanLarı, düşünceleri, durumları ve hareketleri doğru, yanlış, istenilen, istenmeyen ve bunun gibi yargılarımızı oluşturan kabullerimizi ifade eder. $^{6}$

Eğitimde ahlaki değerlerin öğretimi geçmişte de üzerinde durulan bir konudur. Tarihin tüm dönemlerinde ve dünyanın her yerinde tartışılmıştır. ${ }^{7}$ Platon, ahlak eğitiminin okullarda verilmesi gerektiğini düşünmüş ve aklını kendisi ve diğerleri için de kullanabilen vatandaşlar yetiştirmeye odaklanmıştır. ${ }^{8}$ Kirschenbaum $^{9}$ göre, ahlak eğitimi tüm vatandaşlara ahlaklı olmaya yönelik bilgi, inanç, tutum ve davranış ilkelerini kazandırmalıdır. Ahlaki eğitimin temel amac1, bireylerin ahlaki değerleri

Geliş Tarihi/Received:06-06-2017/ Kabul Tarihi/Accepted: 04-10-2017

${ }^{a}$ Yrd.Doç.Dr. Adıyaman Üniversitesi, Sağlık Yüksekokulu, Hemşirelik Bölümü, Adıyaman

Adıyaman Üniversitesi, Sağlık Yüksekokulu, Hemşirelik Bölümü, Adıyaman, e-mail: turkan_20051@ hotmail.com, ORCID ID: 0000-0002-8603-5460

Sorumlu yazar /Correspondence: Yrd.Doç.Dr. Türkan Karaca, Adıyaman Üniversitesi, Sağlık Yüksekokulu, Hemşirelik Bölümü e-mail: turkan_20051@ @otmail.com, 
üzerinde düşünmesi ve değerleriyle iç içe davranışlar göstermesidir. ${ }^{10}$ Ahlaki gelişimin, eğitim süreci içinde gelişme gösterip göstermediği önemli bir konudur. ${ }^{11}$ Sinıf düzeylerini dikkate alarak yapılan çalışmalarda, eğitim basamakları ilerledikçe, ahlaki yargılarda daha üst düzeyde kararlar alındığı gözlenmektedir. ${ }^{12-14}$

Literatür incelendiğinde, hemşirelerin farklı klinik uygulama alanlarında birçok etik ikilem ve ahlaki karar almayı gerektiren durumlarla karşılaştığını saptayan çalışmalar mevcuttur. ${ }^{15-18}$ Nathaniel ${ }^{18}$ yaptığ 1 çalışmada, hemşirelerin en az 1/3'ünün ahlaki sıkıntı yaşadıklarını saptamıştır. Redman ve Fry ${ }^{4}$ ise, hemşireler tarafindan algılanan ahlaki konuları ve ahlaki çatışma alanlarını incelemiş ve hemşirelerin, etik çatışmayı ahlaki bir sıkıntı olarak deneyimlediklerini belirlemişlerdir.

Hemşirelik öğrencilerinin ileride gelişmiş ahlaki duyarlılığa sahip birer hemşire olabilmeleri için öncelikle kendilerinin duygu, inanç ve değerlerinin farkında olması ve sağlık sisteminin getirdiği etik ikilemlerle baş etme becerisi kazandıran bir eğitim programından geçmeleri gerekmektedir. Literatür incelendiğinde, hemşirelik öğrencilerinin ahlaki duyarlılıklarını belirlemeye yönelik sınırlı sayıda çalışmaya rastlanmıştır. Bu doğrultuda araştırma; orta öğretimden gelmiş hemşirelik öğrencilerin ahlaki duyarlılıklarını ortaya koymak, ahlaki duyarlılıkları ile ilişkili faktörleri belirlemek, çalışan ve öğrenimine devam eden sağlık çalışanlarına kaynak oluşturmak amacıyla tanımlayıcı olarak yapılmıştır.

\section{Materyal ve Metod}

\section{Araştırmanın Amacı}

Araştırma, hemşirelik öğrencilerinin ahlaki duyarlılıklarının ve ilişkili faktörlerin incelenmesi nedeniyle tanımlayıcı desende yapıldı.

\section{Araştırmanın Evren ve Örneklemi}

Çalışmanın evreninde 2015-2016 Eğitim ve Ögrretim Y1lında ve Bahar Dönemi'nde Ad1yaman Üniversitesi Sağlık Yüksekokulu Hemşirelik Bölümünde kayıtlı 322 öğrenci yer aldı. Çalışmanın örneklemini araştırmaya ilişkin bilgi aldıktan sonra kendi rızasıyla araştırmaya katılan ve veri toplama araçlarını tam olarak dolduran 281 öğrenci oluşturdu.

\section{Veri Toplama Araçları}

Araştırmada veriler kişisel bilgi formu ve Ahlaki Duyarlılık Anketi kullanılarak toplandı.
Kişisel özellikler formu, öğrencilerin bazı tanımlayıcı özelliklerini saptamak amacıyla belirlenmiş toplam 15 soru içermektedir Tanıtıcı özellikler formunda, öğrencilerin sosyodemografik özellikleri, çalışma durumları, hemşirelik bölümünü isteyerek tercih etme durumları, bölümden memnuniyetleri, etik ile ilgili ders alma durumları ve etik ikilem yaşama sıklıkları sorgulanmıştır.

Ahlaki Duyarlilık Anketi, ahlaki duyarlılığ 1 değerlendirmek için Kim Lutzen tarafindan 1994 yılında geliştirilmiştir. Türkiye'de ölçeğin geçerlik ve güvenirliğini 2005 yılında Tosun ${ }^{19}$ yapmış ve ölçeğin_Cronbach alfa değeri 0.84 olarak saptanmıştır. Yedili likert olarak derecelendirilen 30 madde ve alt1 alt boyuttan (Otonomi,Yarar Sağlama, Bütüncü Yaklaşım, Çatışma, Uygulama, Oryantasyon) oluşan ölçeğin toplam puanı 30-210 aralığında değişmektedir. Ölçekten alınan yüksek puan ahlaki olarak düşük duyarlılığı, düşük puan ise ahlaki olarak yüksek duyarlılı̆̆ mektedir. ${ }^{19}$

\section{Veri Toplama Araçlarının Uygulanması}

Araştırma öğrencilerin eğitim-öğretim yılının ilgili güz döneminin son haftası (14. Hafta) yürütülmüştür. Öğrencilere öğrenim gördükleri sinıflarda veri toplama formları dağıtılmadan önce araştırmaya ilişkin bilgiler verilmiştir. Daha sonra kendi rızasıyla araştırmaya katılmaya kabul eden aydınlatılmış yazılı onam formunu doldurmaları istenmiştir. Aydınlatılmış yazılı onam formunu dolduran öğrencilere kişisel özellikler formu, Ahlaki Duyarlılık Anketi birlikte verilmiş ve ilgili formları eksiksiz doldurmaları istenmiştir.

\section{Verilerin Değerlendirilmesi}

Verilerin değerlendirilmesinde SPSS for Windows 16 istatistik paket programından yararlanılmıştır. Araştırmada anketten alınan puanlar bağımlı değişkenleri, tanıtıcı özellikler formunda yer alan veriler ise bağımsız değişkenleri göstermektedir. İki bağımsız grup karşılaştırmalarında Mann Whitney $U$ testi, ikiden fazla bağımsız grubun karşılaştırılmasında Kruskal-Wallis testi kullanılmıştır. Ayrıca, verilerin analizinde yüzdelik hesapları, ortanca, minimum, maksimum kullanılmıştır.

\section{Araştırmanın Etik Yönü}

Araştırmanın uygulanabilmesi için girişimsel olmayan araştırmalar etik kurulundan (20164/16) ve okul yönetiminden yazılı izin alınmıştır. 
Araştırmaya kendi rızasıyla katılan öğrencilerinden yazılı onam alınmış ve araştırmada veri toplama formlarına kimlik bilgilerini yazmamaları istenmiş ve öğrencilerin gizliliği sağlanmıştır.

\section{Bulgular}

Araştırmaya katılan öğrencilerin sosyolojik, demografik ve etik ile ilgili özellikleri Tablo 1 'de görülmektedir. Büyük çoğunluğu 21-24 yaş aralığında olup, tamamına yakını bekar (\%96.7), \%51.9'u genel lise mezunudur. \%54.4'ü hemşirelik 0bölümünü isteyerek tercih ettiğini, \%40.5'i okuduğu bölümden memnun olduğunu belirtmiştir. \%92.5'i hemşire olarak herhangi bir yerde çalışmamaktadır. Öğrencilerin yarısı (\%53.3) etik ile ilgili her hangi bir ders aldığını ve sadece \%18.1'i etik ile ilgili bir süreli yayını takip ettiğini ve çoğu öğrenci (\%64.4) etik ikilem yaşadığını belirtmiştir (Tablo 1).

Tablo 1. Öğrencilerin Özellikleri

\begin{tabular}{lcc}
\hline Tanıtıcı Özellikler (n=281) & Sayı & \multicolumn{1}{c}{$\%$} \\
\hline Mezun olunan okul & & \\
Genel Lise & 146 & 51.9 \\
Anadolu Lisesi & 94 & 33.4 \\
Sağlık Meslek Lisesi & 22 & 7.9 \\
Süper Lise & 19 & 6.8 \\
\hline Çalısma durumu & & \\
Hayır & 260 & 92.5 \\
Evet & 21 & 7.5 \\
\hline Hemşirelik bölümünü & & \\
tercih durumu & & \\
İsteyerek & 152 & 54.4 \\
İstemeyerek & 129 & 45.6 \\
\hline Hemşirelik bölümünden & & \\
memnuniyet durumu & & \\
Memnunum & 114 & 40.5 \\
Memnun değilim & 93 & 33.0 \\
Kararsızım & 54 & 26.5 \\
\hline Etik ile ilgili ders alma & & \\
durumu & & \\
Evet & 150 & 53.3 \\
Hayır & 131 & 47.7 \\
\hline Etik ile ilgili yayın takip & & \\
etme durumu & & \\
Evet & 51 & 18.1 \\
Hayır & 230 & 81.9 \\
\hline Etik ikilem yaşama durumu & & \\
Evet & 181 & 64.4 \\
Hayır & 100 & 35.6 \\
\hline
\end{tabular}

Öğrencilerin ahlaki duyarlıl1k anketinden ald1kları puan ortalamaları $124.20 \pm 30.6$, medyan değeri 118 ve en düşük puan 30 , en yüksek puan 208'dir (Tablo 2).

Tablo 2. Öğrencilerin Ahlaki Duyarlılık Anketi ve Alt Boyutlarının Tanımlayıcı İstatistikleri

\begin{tabular}{llcc}
\hline $\begin{array}{l}\text { Ahlaki } \\
\text { Duyarlılık } \\
\text { Alt Boyutları }\end{array}$ & Ort \pm S & Medyan & $\begin{array}{c}\text { Min- } \\
\text { Max }\end{array}$ \\
\hline Otonomi & $27.62 \pm 8.81$ & 28 & $7-49$ \\
Yarar Sağlama & $15.82 \pm 4.91$ & 16 & $4-28$ \\
Bütüncül & $15.48 \pm 5.58$ & 15 & $5-28$ \\
Yaklaşım & $13.99 \pm 3.69$ & 13 & $3-21$ \\
Çatışma & $15.49 \pm 4.72$ & 16 & $4-28$ \\
Uygulama & $14.63 \pm 6.29$ & 15 & $4-28$ \\
$\begin{array}{l}\text { Oryantasyon } \\
\text { Ahlaki }\end{array}$ & & & \\
$\begin{array}{l}\text { Duyarlılık } \\
\text { Anketi }\end{array}$ & $124.2 \pm 31.4$ & 118 & 30 \\
\hline
\end{tabular}

Öğrencilerin okudukları sınıf, ahlaki duyarlılık puan medyanlarını istatistiksel olarak anlamlı düzeyde etkilemektedir $(\mathrm{p}=0.011)$. Dördüncü sınıfta yer alan öğrencilerinin anket puan medyanı tüm sınıflar içinde en düşük değere (98.5) sahiptir ve yapılan ileri analizde ise anlamlı farkı yaratan grubun dördüncü sınıf olduğu bulunmuştur (Tablo 3). Yaş gruplarına öğrencilerin ahlaki duyarlılık anketi puan medyanlarının yaşlara göre anlamlı olmadığ 1 görüldü $(\mathrm{p}=0.826) \quad$ (Tablo 3$)$. Anket puan medyanı en düşük olan grup (104.00) 23 yaş ve üzeri iken, 19 yaş ve altında yer alan öğrenciler ise en yüksek anket puan medyanına (114.00) sahiptir.

Sosyo-ekonomik düzeye göre ahlaki duyarlılık anketi puan medyanlarına göre yapılan istatistiksel değerlendirmede ekonomik düzeyler arasında fark vardır $(\mathrm{p}=0.049)$ (Tablo 3 ). Ekonomik durumu orta olan öğrencilerin anket puan medyanları 116.5 iken, yüksek olan öğrencilerin anket puan medyanları 111.0'dır. Hemșirelik bölümünde okumaktan memnun olan öğrencilerin anket puan medyanları (111.0) memnun olmayan (123.0) ve kararsiz (121.5) öğrencilerin anket puan medyanlarından istatistiksel anlamlı olarak daha düşük olduğu görüldü ( $\mathrm{p}=0.043)$ (Tablo 3). Etik ile ilgili herhangi bir ders alan öğrencilerin anket puan medyanları (110.0) almayan ögrrencilerin anket puan medyanlarına göre (123.0) istatistiksel 
Tablo 3. Ahlaki Duyarlılık Anketi Puan Medyanlarının Öğrencilerin Tanıtıcı Özelliklerine Göre Dağılımı $(\mathrm{n}=281)$

\begin{tabular}{|c|c|c|c|c|c|}
\hline \multirow{5}{*}{ Sinıf } & Tanitici & $\mathrm{N}$ & Medyan & Min- Max. & İstatistiksel \\
\hline & 1.Sinif & 43 & 105.50 & $29-203$ & \multirow{4}{*}{$\begin{array}{l}X^{2}=9.905 \\
P=0.011\end{array}$} \\
\hline & 2.Sinif & 82 & 112.00 & 73- 179 & \\
\hline & 3.Sinıf & 60 & 113.00 & $77-178$ & \\
\hline & 4.Sinıf & 96 & 98.50 & $58-155$ & \\
\hline \multirow[t]{3}{*}{ Yaş grupları } & 19- altı yaş & 108 & 114.00 & $29-203$ & \multirow{3}{*}{$\begin{array}{l}X^{2}=0.157 \\
P=0.826\end{array}$} \\
\hline & $20-22$ yaş & 119 & 112.00 & $58-179$ & \\
\hline & 23- üstü yaş & 54 & 104.00 & $69-164$ & \\
\hline \multirow{3}{*}{$\begin{array}{l}\text { Sosyo-ekonomik } \\
\text { Düzey }\end{array}$} & Düşük & 36 & 125.50 & $29-180$ & \multirow{3}{*}{$\begin{array}{l}X^{2}=1.599 \\
P=0.049\end{array}$} \\
\hline & Orta & 208 & 116.50 & $58-203$ & \\
\hline & Yüksek & 37 & 111.00 & $58-203$ & \\
\hline \multirow[t]{4}{*}{ Mezun olunan okul } & Genel Lise & 146 & 115.00 & $58-203$ & \multirow{4}{*}{$\begin{array}{l}X^{2}=0.617 \\
P=0.892\end{array}$} \\
\hline & Anadolu Lisesi & 94 & 113.00 & $29-203$ & \\
\hline & $\begin{array}{l}\text { Sağlık Meslek } \\
\text { Lisesi }\end{array}$ & 22 & 111.00 & $68-137$ & \\
\hline & Süper Lise & 19 & 101.00 & $77-144$ & \\
\hline \multirow{2}{*}{$\begin{array}{l}\text { Hemşirelik bölümünü } \\
\text { tercih etme durumu }\end{array}$} & İsteyerek & 152 & 115.00 & $29-193$ & \multirow[b]{2}{*}{$\begin{array}{l}Z=-0.307 \\
P=0.769\end{array}$} \\
\hline & İstemeyerek & 129 & 117.50 & $58-172$ & \\
\hline \multirow{3}{*}{$\begin{array}{l}\text { Hemşirelik } \\
\text { bölümünden } \\
\text { memnuniyet durumu }\end{array}$} & Memnun & 114 & 111.00 & $29-203$ & \multirow{3}{*}{$\begin{array}{l}X^{2}=5.892 \\
P=0.043\end{array}$} \\
\hline & $\begin{array}{l}\text { Memnun } \\
\text { değilim }\end{array}$ & 93 & 123.00 & $81-180$ & \\
\hline & Kararsızım & 54 & 121.50 & $58-156$ & \\
\hline \multirow{2}{*}{$\begin{array}{l}\text { Etik ile ilgili ders alma } \\
\text { durumu }(\mathrm{n}=153)\end{array}$} & Evet & 50 & 110.00 & $29-203$ & \multirow[b]{2}{*}{$\begin{array}{l}Z=-1.526 \\
P=0.030\end{array}$} \\
\hline & Hayır & 103 & 123.00 & $58-178$ & \\
\hline \multirow{2}{*}{$\begin{array}{l}\text { Etik ile ilgili yayın } \\
\text { takip etme durumu }\end{array}$} & Evet & 21 & 112.00 & $77-155$ & \multirow[b]{2}{*}{$\begin{array}{l}Z=-0.718 \\
P=0.049\end{array}$} \\
\hline & Hayır & 132 & 119.00 & $29-203$ & \\
\hline \multirow{2}{*}{$\begin{array}{l}\text { Etik ikilem yaşama } \\
\text { durumu }\end{array}$} & Evet & 66 & 112.00 & $69-178$ & \multirow[b]{2}{*}{$\begin{array}{l}Z=-1.283 \\
P=0.016\end{array}$} \\
\hline & Hayır & 87 & 128.00 & 29-203 & \\
\hline
\end{tabular}

anlamlı olarak daha düşük değere sahiptir $(\mathrm{p}=0.03)$ (Tablo 3).

Yapılan istatistiksel değerlendirmede öğrencilerin ahlaki duyarlılık anketi puan medyanlarının hemşirelik bölümünden memnuniyet durumlarına göre farklı olduğu görüldü $(\mathrm{p}=0.043)$ (Tablo 3).

Etik ile ilgili herhangi bir süreli yayını takip eden öğrencilerin anket puan medyanları (112.0) takip etmeyen öğrencilerin anket puan medyanlarından (119.0) daha düşük değere sahiptir. Yapılan istatistiksel değerlendirmede öğrencilerin ahlaki duyarlılık anketi puan medyanlarından herhangi bir süreli yayını takip etme durumuna göre anlaml olduğu görüldü $(\mathrm{p}=0.049)$ (Tablo 3). Etik ikilem yaşayan öğrencilerin anket puan medyanları (112.0) yaşamayan öğrencilerin anket puan medyanlarından (128.0) daha düşük değere sahiptir. Yapılan istatistiksel değerlendirmede öğrencilerin ahlaki 
duyarlılık anketi puan medyanları etik ikilem yaşama durumlarına göre farklı olduğu bulundu $(\mathrm{p}=0.016)($ Tablo3 $)$.

\section{Tartışma}

Ahlaki duyarlılık anketinden alınabilecek en yüksek puanın 230, en düşük puanın 30 olduğu ve puan düştükçe ahlaki duyarlılığın arttığı düşünüldüğünde, öğrencilerin puan ortalamalarının orta düzeyde olduğu (124.2) görülmektedir. Ahlaki duyarlılık anketi kullanılarak yapılan çalışmalar incelendiğinde, Eraydın ve Albayrak $^{20}$ (2015) tarafindan bir üniversitenin hemşirelik bölümlerinde okuyan öğrencileri ile yapılan çalışmada öğrencilerin anket puan ortalamaları benzer şekilde (111.8) olduğu saptandı. Hemşirelik öğrencileri ile yapılan başka bir çalışmada ise öğrencilerin ahlaki duyarl111k anketi puan ortalamalar1 85.93 olarak bulunmuştur. ${ }^{21} \mathrm{Bu}$ durum hemşirelik öğretim müfredatlarının benzer olmasına karşın öğretimi etkileyen diğer faktörlerin (öğretici özellikleri, araç-gereçlerin durumu, öğrenenlerin hazır oluşluk düzeylerinin farklı olması vb.) bu çalışmaların yapıldığg kurumlarda daha iyi düzenlenmesinden kaynaklanabilir.

Dördüncü sınıfta yer alan öğrencilerinin anket puan medyanları tüm sinıflar içinde olup en düşük değere (98.50) sahiptir. Ögrencilerin okudukları sınıf, ahlaki duyarlılık puan medyanların istatistiksel olarak anlamlı düzeyde etkilemektedir $(\mathrm{p}<0.05)$. Yapılan ileri analizde ise anlamlı fark1 yaratan grubun dördüncü sınıf olduğu bulundu. Birinci sınıfta yer alan hemşireliğe giriş dersi öğrencilerin ilk karşılaştıkları mesleğe özgü ders olma özelliğindedir. Hemşireliğe giriş ders programı içeriği ağırlıklı olarak hasta güvenliği ve mahremiyeti, hasta onamı, hasta hakları gibi temel kavramlara yönelik bilgi ve uygulamaları içermektedir. Dolayısıyla öğrencilerin edindikleri bilgiler doğrultusunda ahlaki duyarlılıklarının gelişmiş olması düşünülebilir. Dördüncü sınıf ise son sinıf olup ve bu döneme gelinceye kadar öğrenciler gerek temel dersleri (Hemşirelik Esasları, Cerrahi Hemşireliği, Psikiatri Hemşireliği v.b.), gerekse diğer dersler kapsamında (Kişiler Arası İlişkiler, Beslenme İlkeleri, Sosyoloji, Psikoloji v.b.) ahlaki duyarlılıklarını geliştirebilmelerine katkı sağlayabilecek bilgiler edinmekte ve çeşitli öğrenme ortamlarında bulunmaktadırlar. Bu nedenle son sınıf öğrencilerin ahlaki duyarlılıklarının daha gelişmiş olması beklenen bir sonuçtur. Hemşirelik öğrencileri ile yapılan çalışmaların bulguları da bu görüşü destekler niteliktedir. ${ }^{20-21}$ Yaşın yükselmesi ile puan medyanlarında azalış olduğu görülmektedir ancak gruplar arasında anlamlı bir fark bulunmamıştır. Bununla beraber yaş ile ahlaki duyarlılık anket puanları arasinda anlamlı bir ilişkinin olduğunu ve ilerleyen yaşla beraber ahlaki duyarlılığın arttığını gösteren farklı disiplinlerde yapılan çalışmalar da bulunmaktadır. ${ }^{22-25}$ Çalışmamızda yaş gruplarına göre hemşirelik öğrencilerinin ahlaki duyarlılıklarının farklı çıkmaması öğrencilerin yaşlarının birbirine yakın olmasından kaynaklandığ 1 düşünülebilir.

Öğrencilerin ekonomik düzeyi arttıkça ahlaki duyarlılık anket puan medyanlarının azaldığı ve gruplar arasında anlamlı bir fark bulunduğu saptanmıştır. Ekonomik düzeyin artmasının yaşam şartlarının yükselmesine kültürel birikimin artmasına ve dolayısıyla olaylara farklı bakış açıları geliştirilmesine neden olarak öğrencilerin ahlaki duyarlılıklarını olumlu yönde etkilediği söylenebilir.

Hemşirelik bölümünden memnuniyet durumu incelendiğinde, memnun olan ve olmayan gruplar arasında anlamlı bir fark vardır. Ahlaki duyarlılık ile ilgili yapılan çalışma sonuçlarında da okuduğu bölümden memnun olan ögrencilerin ahlaki duyarlılık anket puan ortalamaları daha düşük saptandığı görülmektedir. ${ }^{19,21,23}$ Mesleğini isteyerek seçme ve severek yapma gibi faktörlerin olumlu sonuca yol açmasının doğal olduğu söylenebilir.

Etik dersi alan öğrencilerin anket puan medyanları almayan öğrencilerden daha düşük değerdedir ve gruplar arasında anlamlı bir fark vardır. Ahlaki duyarlılık anketi ile yapılan diğer çalışmalarda da lisans eğitiminde etik dersi alan bireylerin ahlaki duyarlılıklarının daha fazla olduğu görülmektedir. ${ }^{19,2}$ Bununla beraber hemşireler ve hekimlerle yapılan diğer çalışma-larda, mesleki eğitimleri esnasında etik ile ilgili bir ders alma durumlarına göre etik duyarlılığın toplam puanları açısından gruplar arasında önemli bir fark bulunmadığını gösteren çalışmalar da mevcuttur. ${ }^{23,25,27}$ Lisans eğitiminde etik ögretiminin önemi konusunda fikir birliği bulunmaktadır ancak etik öğretiminin nasıl verileceğine yönelik fikir birliğinin bulunmaması farklı sonuçların oluşmasına neden olabilir. ${ }^{28,29}$.

Öğrencilerin etik ile ilgili yayın takip etme durumlarına bakıldığında, etik yayın takip eden öğrencilerin sayısının oldukça az ve anket puan medyanlarının etmeyen öğrencilerden daha 
düşük değerde olduğu saptandı. $\mathrm{Bu}$ duruma neden olarak öğrencilerin süreli yayın takip etme alışkanlıklarının olmaması ve ekonomik sorunlar gösterilebilir.

Çalışmada etik ikilem yaşayan öğrencilerin anket puan medyanları yaşamayan öğrencilerden daha düşük değerdedir ve gruplar arasında anlamlı bir ilişki bulundu $(\mathrm{p}<0.05)$. Etik ikilem yaşama durumu mutlak doğru ya da yanlış kararların seçilemediği bir durumdur. Bu durum öğrencilerde etik kavramlar ve etik ikilem konusunda farkındalık oluşturulması gerektiğine işaret etmektedir.

\section{Sonuçlar ve Öneriler}

Çalışmada hemşirelik öğrencilerinin puanla-

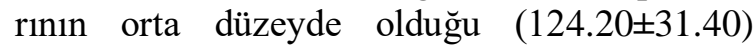
görülmektedir. Ayrıca araştırmada elde edilen sonuçlara göre, ahlaki duyarlılık anketi ile ögrencilerin sınıfları, sosyo-ekonomik düzeyleri, hemşirelik bölümünden memnuniyetleri, etik dersi alma ve etikle ilgili yayın takip etme durumları, etik ikilemde kalma durumları ile istatistiksel olarak anlamlı fark saptanmıştır. Hemşirelik öğrencilerinin ahlaki duyarlılı̆̆ının artırılması ve buna bağlı olarak etik sorunların farkına varma ve çözümünün bulunulabilmesi için, mezun olmadan önce ve sonra etiğe ilişkin eğitim programlarının geliştirilmesi ve bu konuda daha fazla araştırma yapılması öneriler arasindadir.

\section{Kaynaklar}

1. Özcan M, Akpınar A, Ergin AB. Personal and professional values grading among midwifery students. Nurs Ethics, 2012; 19:3 399-407.

2. Aydın İp. Yönetsel mesleki ve örgütsel etik. Ankara: Pegem Yayıncılık 2012.

3. Babadağ, K. Hemşirelikte etik. Hemşirelikte Etik Bülteni, 1991; 19:5 5-9.

4. Redman BK, Fry S. Nurses' ethical conflicts: what is really known about them, Nursing Ethics, 2000; 7:4 360-366.

5. Kim YS, Park JW, Son YJ. A Longitudinal Study on the Development of Moral Judgement in Korean Nursing Students. Nursing Ethics, 2004; 11:3 254-265.

6. Halstead J. Taylor MJ. Learning and teaching about values: a review of recent research. Cambridge Journal of Education, 2000; 30:2 169-202.

7. Akbaş O. Değer eğitimi akınlarına genel bir bakış. Değerler Eğitimi Dergisi, 2008; 6:16 9-25.
8. Lickona T. Educating for character (How our schools can teach respect and resposibility). New York: Bantam Books 1992.

9. Kirschenbaum, H. 100 ways to enhance values and morality in schools and youth settings. Massachusetts: Allyn\&Bacon Company 1995.

10.Dewey, J. Okulda ahlak eğitimi. (çev: A.Ferhan Oğuzkan). 1959, www.dergiler.ankara.edu.tr/dergiler/40/496/ 5860.pdf

11.İz FB, Özsoy SA. Kohlberg' in bilişsel ahlak gelişimi kuramına göre hemşire öğrencilerin ahlaki yarg1 yeteneklerinin belirlenmesi. Yayınlanmamış doktora tezi İzmir: Ege Üniversitesi Sağl1k Bilimleri Enstitüsü 2009.

12.Sanchez, TR. Heroes, Values, and Transcending Time: Using Trade Books to Teach Values. 1998, www.eric.ed.gov , ERİC Document No: ED 426923.

13.Çiftçi N. Almanya ve Türkiye'deki lise öğrencilerinin ahlaki yarg1 yeteneklerinin karş1laştırılması. Yayınlanmamış doktora tezi İstanbul: Marmara Üniversitesi Sosyal Bilimler Enstitüsü 2001.

14.Çırak KG. Üniversite öğrencilerinin ahlaki yargı yetenekleri ve ahlaki yargı yetenekleri ile kendini gerçekleştirme düzeylerinin karşılaştırılması. Yüksek lisans tezi Adana: Çukurova Üniversitesi Sosyal Bilimler Enstitüsü 2006.

15.Rushton $\mathrm{CH}$, Scanlon,C. When values conflict with obligations: safeguards for nurses, Pediatric Nursing, 1995; 21 260-268.

16. Katsuhara Y. What moral requirements cause ethical dilemmas among nurse executives. Academy of Nursing Science, 2005; 23:3 110.

17.Keskin G,Yıldırım GÖ. Hemşirelerin Kişisel Değerlerinin ve İş Doyumlarının İncelenmesi, Ege Üniversitesi Hemşirelik Yüksekokulu Dergisi, 2006; 22:1 119-133.

18. Nathaniel KA. Moral Reckogning in nursing, Western Journal of Nursing Research, 2006; 28:4 419-438.

19.Tosun H. Sağlık bakım uygulamalarında deneyimlenen etik ikilemlere karşı hekim ve hemşirelerin etik duyarlılıklarının belirlenmesi. Yayınlanmamış yüksek lisans tezi İstanbul: İstanbul Üniversitesi Sağlik Bilimleri Enstitüsü 2005.

20.Eraydın Ş, Albayrak K. Hemşirelik öğrencilerinin kişisel değerleri ve etik duyarlilıklarının incelenmesi (2015). 15.Ulusal Hemşirelik Öğrencisi Kongresi. 
21.Selçuk TK, Demir C. Hemşirelik bölümü öğrencilerinin etik duyarlılık düzeyi ve etkileyen etmenler (2015). 15.Ulusal Hemşirelik Öğrencisi Kongresi.

22.Lutzen K, Evertson M, Nordin C. Moral sensitivity in psychiatric practice. Nursing Ethics, 1997; 52 76-81.

23.Pekcan HS. Yalova ili ve çevresinde görev yapan hekimlerin ve hemşirelerin etik duyarlılıkları. Yayınlanmamış yüksek lisans tezi İstanbul:Marmara Üniversitesi Sağl1k Bilimleri Enstitüsü 2007.

24.Dikmen Y. Yoğun bakım hemşirelerinde etik duyarlılığın incelenmesi. Cumhuriyet Üniversitesi Hemşirelik Fakültesi Dergisi, 2013; 2:1 1-7.

25. Tazegün A. Çocuk hemşirelerinin etik duyarlılık düzeyleri ve etkileyen faktörler. Yayınlanmamış yüksek lisans tezi Erzurum: Atatürk Üniversitesi Sağlık Bilimleri Enstitüsü 2013.

26.Gül Ş, Duru G, Kahraman B, Büken N. Etik dersi alan ve almayan hemşirelik öğrencilerinin etik karar verebilme düzeylerinin incelenmesi. Hemar-G, 2013; 1 23-31.
27.Başak T, Uzun Ş, Arslan F. Yoğun bakım hemşirelerinin etik duyarlılıklarının incelenmesi. Gülhane Tip Dergisi, 52 76-81.

28. Haigh C, Johnson M. Attitudes and values of nurse educators. An international survey. International Journal of Nursing Education Scholarship, 2007;4:1 520-533.

29. Görgülü RS, Dinç L. Ethics in Turkish nursing education programs. Nursing Ethics, 2007; 14:6 741-52. 